\title{
Energy Balances and Payback Time for Controlled Mechanical Ventilation in Residential Buildings
}

\author{
Gianpiero Evola *, Luigi Marletta, Antonio Gagliano, Francesco Nocera and Desirée Peci \\ Dipartimento di Ingegneria Elettrica, Elettronica e Informatica, University of Catania, V.le A. \\ Doria 6, 95125 Catania (Italy) \\ Email: gevola@unict.it
}

\begin{abstract}
In residential buildings, air renewal is usually entrusted to the occupants, who open windows at will. On the other hand, a controlled mechanical ventilation system (MV) may provide fresh outdoor air by mechanical means, thus diluting indoor pollutants and improving the indoor air quality (IAQ).

The aim of this paper is to evaluate the technical features of controlled MV systems and their energy and financial appropriateness in residential buildings. Several configurations of mechanical ventilation system are designed for a reference residential unit located in various locations of Italy, covering a wide range of climates. For each configuration (single-flow, double-flow) the overall cost for installation is calculated. Therefore, for all the configurations of MV system, the electric energy to feed the fan and the thermal energy to counterbalance the heating needs due to the ventilation are determined, and compared to the energy needs in a building without any mechanical ventilation system.

The results show that mechanical ventilation introduces considerable primary energy savings, with an attractive payback time of the investment especially in cold climates. This makes mechanical ventilation systems an appealing technology for reaching the target of Zero Energy Buildings.
\end{abstract}

Keywords: Mechanical ventilation, Residential buildings, Heat recovery, Primary energy, Costs.

\section{INTRODUCTION}

Building ventilation, that is to say the natural or mechanical inlet of outdoor air, is one of the terms which contribute to the energy consumption for space heating. Natural ventilation usually comes from the intentional opening of the windows by the occupants, pushed by the desire to improve the indoor air quality (IAQ). A minor contribution occurs through cracks and vents, and this depends by the air tightness of the envelope. In both cases, the air flow is a function of the difference of temperature and pressure between indoor and outdoor environment [1].

Now, it is necessary to highlight that new buildings are characterized by low heat losses through the envelope, and natural ventilation has come to represent a noteworthy share of the energy needs for space heating.

However, houses have also become more and more tightly sealed, mainly by adopting windows with very low permeability to air.

The air-tightness of the envelope is defined by the parameter $\mathrm{n}_{50}$, which is the number of air changes per hour under a pressure differential of $50 \mathrm{~Pa}$. Passivhaus standard, suggests that $\mathrm{n}_{50}$ must be below $0.6 \mathrm{~h}^{-1}$; on the other hand, Italian regulations recommend $\mathrm{n}_{50}<2 \mathrm{~h}^{-1}$ for single-family houses and $\mathrm{n}_{50}<1 \mathrm{~h}^{-1}$ otherwise.
Air tightness implies the difficulty to ensure enough outdoor air, necessary to dilute pollutants and odors, provide good IAQ and control the relative humidity. This question cannot be neglected, since insufficient ventilation can cause adverse health effects for the occupants [2].

To meet these two requirements, namely to ensure air renewal and to minimize heat losses, the adoption of controlled Mechanical Ventilation (MV) systems provides a possible solution.

MV plants can be basically classified in single-flow and double-flow systems. Single-flow MV systems foresee air extraction through terminals installed in wet rooms (kitchen, bathrooms) and connected to a fan through conduits, while air supply to living rooms is achieved by means of vents installed on the outer envelope that operate thanks to the negative pressure gradient. This kind of MV systems must be carefully designed, as the permeability of the envelope may significantly affect their performance [3].

Double-flow MV systems foresee air extraction from wet rooms and air supply to living rooms through two separate conduits. In this case two fans are necessary, which implies higher electricity needs for their operation than in single-flow systems; difficulties may also arise with the allocation of the ventilating unit $[4,5]$. However, this configuration also allows to pre-heat supply air from the exhaust air implementing a heat recovery (HR). 
In this sense, Hekmat et al. reported that, by using a MV system equipped with a $\mathrm{HR}$, the total energy consumption can be reduced up to $20 \%$, and that the choice of the ventilation strategy can significantly reduce the energy consumptions [6]. Fukushima et al. reported that the primary energy consumption of a double-flow MV system can be reduced by $25 \%$ with respect to single-flow MV systems, by adopting low-energy fans and a high-efficiency heat exchanger [7]. However, the results of this comparison are strongly influenced by the efficiency of the heating system: indeed, the higher the efficiency, the lower the importance of the HR [8].

Nevertheless, despite all these attractive features MV systems are still not very widespread especially in residential applications. In Italy, just $1 \%$ of the total number of dwellings in the existing building stock is provided with a MV system, either with or without heat recovery, whereas in France this rate raises to $35 \%$ [9]. According to a survey, the main reason for not adopting a MV system, even if available, is the high cost of operation for about $58 \%$ of responders; other main concerns are the difficulty of operation $(21 \%)$ and the noise produced by the fan $(8 \%)$ [10]. Another remarkable study [11], conducted in UK over 20 buildings equipped with heat-recovery double-flow ventilation, points out that less than $10 \%$ of the occupants keep their MV system continuously in operation throughout the year; about $50 \%$ of them keep the system constantly switched off, and prefer to open windows at will.

Finally, Beko et al. highlighted that MV systems with heat recovery are associated with additional capital and maintenance costs, and are supposed to have potential health implications if the maintenance is not adequately conducted. They also often require a change in user habits [12].

In the present study the above mentioned issues will be further investigated, with the aim to cast light on the technical, energy and financial suitability of MV systems in residential applications.

\section{THE CASE STUDY}

\subsection{Description of the dwelling}

The plans of the residential building considered in this study are shown in Fig. 1. It is a single-family house with three floors: the ground floor hosts the living room and the kitchen, whereas the first floor contains three bedrooms and a bathroom. The second floor is an attic, which must not be equipped with mechanical ventilation, since there is no need for air renewal.

Figure 1 identifies the rooms where air has to be supplied or extracted by the controlled mechanical ventilation system. The overall net horizontal surface of the building is $A_{b}=$ $161.7 \mathrm{~m}^{2}$; however, the surface interested by the mechanical ventilation system, i.e. ground and first floor, is $A=109.4 \mathrm{~m}^{2}$, with a corresponding volume $\mathrm{V}=306.4 \mathrm{~m}^{3}$.

The building has a reinforced concrete structure, very common in Mediterranean countries. The outside walls are composed of a single layer of lightweight clay blocks $(30 \mathrm{~cm})$, insulated from the outer side $(4 \mathrm{~cm})$. The transmittance is $\mathrm{U}=$ $0.35 \mathrm{~W} \mathrm{~m}^{-2} \mathrm{~K}^{-1}$, and it is below the recommended threshold for new buildings in Italy. As for the floor slabs, they consist of a $20-\mathrm{cm}$ slab made of reinforced concrete and hollow bricks, covered with a concrete screed to fall $(5 \mathrm{~cm})$ and a tiled floor.
The windows are provided double 4-mm sealed glazing filled with argon and thermal-break aluminum profiles; the inner pane is treated with a low-emissive coating, with an overall $\mathrm{U}=3.1 \mathrm{~W} \mathrm{~m}^{-2} \mathrm{~K}^{-1}$.

This building described in this section corresponds to the design of a real building that will be built in Catania, a town on the Eastern coast of Sicily, in Southern Italy. Here, the climate is warm in winter, as witnessed by the low Heating Degree Days $\left(\mathrm{HDD}=833^{\circ} \mathrm{C} \cdot\right.$ day), defined with reference to a base outdoor temperature of $12^{\circ} \mathrm{C}$.

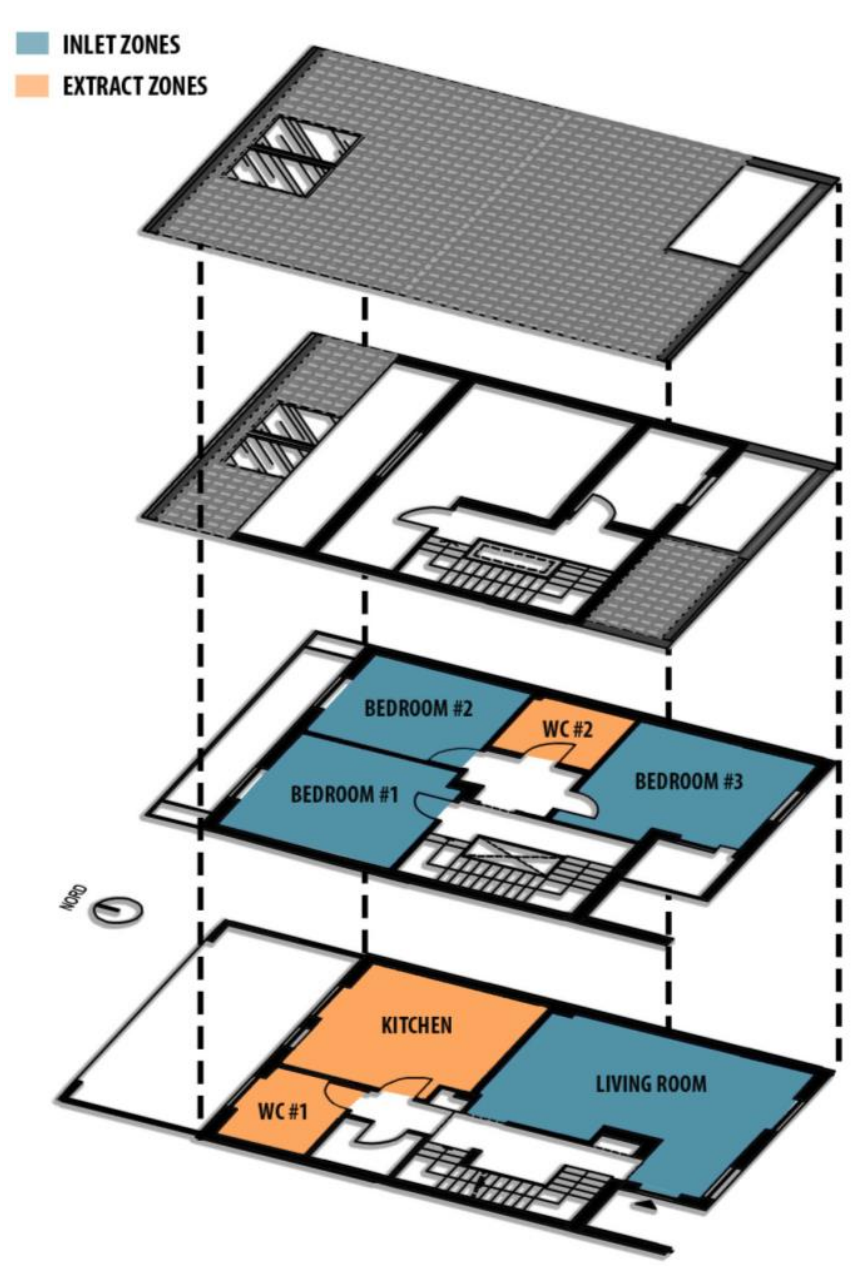

Figure 1. Plans of the dwelling selected as a case study.

Table 1. Useful floor area and net volume for the main rooms

\begin{tabular}{ccc}
\hline Room & $\mathrm{A}\left[\mathrm{m}^{2}\right]$ & $\mathrm{V}\left[\mathrm{m}^{3}\right]$ \\
\hline Kitchen & 17.4 & 48.7 \\
Living room & 27 & 75.6 \\
WC \#1 & 6 & 16.7 \\
Bedroom \#1 & 15.8 & 44.4 \\
Bedroom \#2 & 12.1 & 33.9 \\
WC \#2 & 5.2 & 14.4 \\
Bedroom \#3 & 16.8 & 47.0 \\
Corridors & 6 & 16.7
\end{tabular}

\subsection{Configurations for controlled mechanical ventilation}

With reference to the building previously described, four possible configurations of the controlled mechanical ventilation systems will be investigated, namely: 
- $\quad$ Single-flow MV with constant-flow terminals;

- Single-flow MV with hygro-adjustable terminals;

- Double-flow MV with constant-flow terminals;

- Double-flow MV with hygro-adjustable terminals;

In particular, hygro-adjustable terminals are equipped with a nylon membrane, which modifies its shape when exposed to moisture. This allows to automatically modulate the aperture size of the terminal as a function of the presence of occupants, resulting in a modulation of the rate of ventilation when combined with a constant pressure / variable volume fan unit. As an example, most hygro-adjustable extract units available on the market can modulate the rate of ventilation between 6 $\mathrm{m}^{3} / \mathrm{h}$ at $\mathrm{RH} \leq 30 \%$ and $45 \mathrm{~m}^{3} / \mathrm{h}$ at $\mathrm{RH} \geq 70 \%$. The extract units usually installed in the kitchen may manage, for a short time lapse (usually 30 minutes), a peak air flow rate. The occupants can control the activation of this peak regime by operating on a switch or a remote control.

On the other hand, constant-flow terminals are equipped with a membrane that can modify its shape according to the pressure made available from the fan, thus allowing for an almost constant rate of ventilation. With this kind of terminals, rooms are ventilated by a constant rate of outdoor air (e.g. 15, 22,30 or $45 \mathrm{~m}^{3} / \mathrm{h}$, according to the commercially available size). As for hygro-adjustable terminals, the extract unit in the kitchen can boost the ventilation rate on demand.

Constant-flow terminals are slightly cheaper than hygroadjustable terminals; however, hygro-adjustable terminals allow to save thermal energy [13]. A study carried out in France by the CSTB has shown that the energy savings associated with hygro-adjustable terminals range between $25 \%$ and $60 \%$ of the heat losses for ventilation, depending on the type of dwelling and the conditions of occupancy. Furthermore, additional savings of electricity arise. However, there is very poor literature to confirm these figures; the results of this paper will cast light on this issue.

\section{VENTILATION SYSTEM: SIZE AND COSTS}

\subsection{Required ventilation rate for air renewal}

The calculation of the rate of ventilation needed to dilute pollutants and assure indoor air quality in residential units can be carried out according to different approaches.

The Italian standard UNI 10339:1995 prescribes to ventilate residential units with at least $11 \mathrm{~L} / \mathrm{s}$ per person [14]. In this case study, the dwelling is designed to host $\mathrm{N}_{\mathrm{p}}=4$ people, hence the nominal rate of ventilation is:

$\mathrm{Q}_{\mathrm{UNI}}=\mathrm{N}_{\mathrm{p}} \cdot 11[\mathrm{l} / \mathrm{s}]=55[1 / \mathrm{s}]=158.4\left[\mathrm{~m}^{3} / \mathrm{h}\right]$

On the other hand, a performance-oriented approach is suggested by the European technical report CEN TR 14788 follows [15]. Here, $\mathrm{CO}_{2}$ is identified as the tracer pollutant, and the ventilation rate is calculated in order to dilute $\mathrm{CO}_{2}$ concentration below a threshold of acceptability $\left(\mathrm{y}_{\mathrm{i}}=800\right.$ $\mathrm{ppm})$. The calculation considers the $\mathrm{CO}_{2}$ concentration outdoors $\left(\mathrm{y}_{\mathrm{o}}=400 \mathrm{ppm}\right)$ and its rate of release due to human respiration $\left(\mathrm{q}_{\mathrm{D}}=18 \mathrm{~L} / \mathrm{h}\right.$ per person in the daytime and $\mathrm{q}_{\mathrm{N}}=$ $12 \mathrm{~L} / \mathrm{h}$ per person at night). If one considers $t_{D}=16 \mathrm{~h}$ and $t_{N}$ $=8 \mathrm{~h}$ as the diurnal and nocturnal time of occupancy, respectively, the required mean rate of ventilation is:
$\mathrm{Q}_{\mathrm{CEN}}=\frac{\mathrm{N}_{\mathrm{p}} \cdot\left(\mathrm{q}_{\mathrm{D}} \cdot \mathrm{t}_{\mathrm{D}}+\mathrm{q}_{\mathrm{N}} \cdot \mathrm{t}_{\mathrm{N}}\right)}{\mathrm{y}_{\mathrm{i}}-\mathrm{y}_{\mathrm{o}}} \cdot \frac{1}{24}=160\left[\mathrm{~m}^{3} / \mathrm{h}\right]$

Finally, a much more detailed approach to the definition of the ventilation rates is available in the French regulations [16]. Here, the exact rate of ventilation depends on the type of mechanical ventilation system and on the number of main rooms in the dwelling. Table 2 reports the values prescribed for a residential unit with four main rooms.

It is interesting to underline that with constant-flow terminals it is possible to envisage only two modes of operation: in the base regime, minimum ventilation rates are extracted from all wet-rooms, whereas in the peak regime just the extract terminal in the kitchen operates at its peak. On the other hand, in the base regime hygro-adjustable terminals may modify their ventilation rate within a quite broad range, according to the indoor relative humidity.

It is also necessary to remark that the three different regulations lead to very similar results, since the nominal ventilation rate ranges between 158 and $165 \mathrm{~m}^{3} / \mathrm{h}$. In this paper, the recommendations of the French regulation are retained to size the MV system and to assess the energy needs, due to their higher degree of detail.

To simplify the calculation, when dealing with hygroadjustable systems three main regimes are introduced, as described in Table 3, where the corresponding frequency of occurrence (f) is also reported, both for single-flow (S) and double-flow (D) systems. Basically, the base regime holds when occupants are not at home, while the peak regime occurs when people are at home and the peak flow in the kitchen is activated. The intermediate regime corresponds to an intermediate situation.

Table 3 also provides information about the electric power absorbed by the ventilating unit in all regimes. The values are gained from the technical sheets provided by manufacturers.

Table 2. Prescribed ventilation rates in France $\left(\mathrm{m}^{3} / \mathrm{h}\right)[16]$

\begin{tabular}{|c|c|c|c|c|}
\hline Type & Kitchen & WC \#1 & WC \#2 & Total \\
\hline \multirow{2}{*}{$\begin{array}{c}\text { Constant } \\
\text { flow }\end{array}$} & Peak: 120 & \multirow{2}{*}{30} & \multirow{2}{*}{15} & Peak: 165 \\
\hline & Base: 45 & & & Base: 90 \\
\hline \multirow{2}{*}{$\begin{array}{c}\text { Hygro } \\
\text { adjustable }\end{array}$} & Peak: 120 & \multirow{2}{*}{$5 / 30$} & \multirow{2}{*}{$5 / 15$} & Peak: 165 \\
\hline & Base: 10/45 & & & Base: 20/90 \\
\hline
\end{tabular}

Table 3. Proposed flow regimes for the MV configurations

\begin{tabular}{ccccc|c}
\hline \multirow{2}{*}{ Type } & \multirow{2}{*}{ Regime } & \multirow{2}{*}{$\mathrm{G}\left[\mathrm{m}^{3} / \mathrm{h}\right]$} & \multirow{2}{*}{$\mathrm{f}[\%]$} & \multicolumn{2}{c}{$\mathrm{P}_{\mathrm{el}}[\mathrm{W}]$} \\
\hline \multirow{2}{*}{$\begin{array}{c}\text { Constant } \\
\text { flow }\end{array}$} & Peak & 165 & $10 \%$ & 21 & 95 \\
\cline { 2 - 6 } & Base & 90 & $90 \%$ & 12 & 40 \\
\hline \multirow{2}{*}{$\begin{array}{c}\text { Hygro } \\
\text { adjustable }\end{array}$} & Peak & 165 & $10 \%$ & 21 & 95 \\
\cline { 2 - 6 } & Intermediate & 80 & $60 \%$ & 13 & 38 \\
\cline { 2 - 6 } & Base & 30 & $30 \%$ & 7.5 & 25 \\
\hline
\end{tabular}

Starting from the data in Table 3 , it is possible to assess the average daily air change rate according to Eq. (3):

$\overline{\mathrm{n}}=\frac{\sum_{\mathrm{k}}\left(\mathrm{Q}_{\mathrm{k}} \cdot \mathrm{f}_{\mathrm{k}}\right)}{\mathrm{V}}$ 
As a result, $\overline{\mathrm{n}}=0.32 \mathrm{~h}^{-1}$ for constant flow and $\overline{\mathrm{n}}=0.24 \mathrm{~h}^{-1}$ with hygro-adjustable flow.

\subsection{Calculation of the initial costs}

For all the MV systems proposed in the previous section (constant or hygro-adjustable ventilation rate, single or double flow), a list of components to be installed in the reference building has been made.

To this aim, detailed technical documentation provided by some manufacturers were consulted; the manufacturers are well known on an international scale. The list includes all components needed for a functioning and complete installation, such as:

- Inlet terminals for the living rooms;

- Extract terminals for the wet-rooms;

- Ventilating unit (with two fans and heat recovery in case of double-flow systems);

- $\quad$ Circular ducts (diameter 80 and $125 \mathrm{~mm}$ );

- Aeraulic components.

Hence, the overall cost is calculated. The costs include the purchase of the components (VAT included), the installation by skilled workers and any other masonry work to install and conceal the ducts.

Figure 2 reports the results of this research for all the proposed MV configurations, and the percentage distribution of the costs for equipment and installation. The costs range from around $1150 €$ for constant single-flow systems to around $3950 €$ for hygro-adjustable double-flow systems. Overall, for a given solution (i.e. constant or hygro-adjustable flow) the cost of a double-flow system is more than twice as high as for a single-flow system.

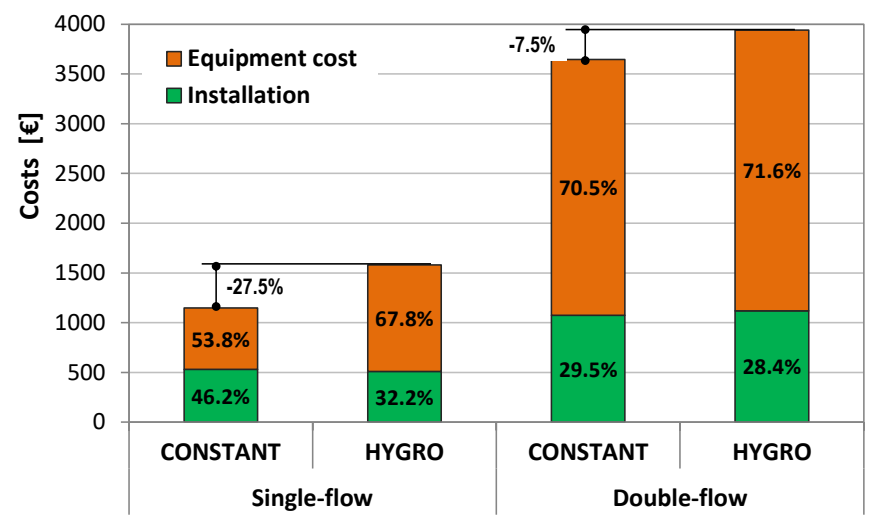

Figure 2. CMV systems: costs for equipment and installation

\section{RESULTS AND DISCUSSION}

\subsection{Final and primary energy consumption}

The financial suitability of mechanical ventilation systems in residential buildings depends on whether the savings of thermal energy for space heating determined by a controlled ventilation rate are sufficient to counterbalance the electricity consumption to operate the fan.

The results presented hereafter try to answer this question, by evaluating the overall energy consumption for all the proposed mechanical ventilation schemes applied to the building presented in Section 2.1 .
In particular, the thermal energy needs for space heating in winter, associated with the introduction of fresh outdoor air for ventilation purposes, can be determined through Eq. (4):

$$
\mathrm{E}_{\mathrm{th}}=\frac{\rho \cdot \overline{\mathrm{n}} \cdot \mathrm{V} \cdot \mathrm{c}_{\mathrm{p}} \cdot \mathrm{HDD} \cdot 24}{3.6 \cdot 10^{6}} \cdot\left(1-\eta_{\mathrm{hr}}\right)
$$

Equation (4) implies that the thermal energy needs are a function of the Heating Degree Days (HDD). Here, $\rho=1.25$ $\mathrm{kg} \mathrm{m}^{-3}$ and $\mathrm{c}_{\mathrm{p}}=1005 \mathrm{~J} \mathrm{~kg}^{-1} \mathrm{~K}^{-1}$. The values of the average ventilation rate are those already presented in Section 3.1.

The term $\eta_{\text {hr }}$ is the efficiency of the heat recovery unit, which is relevant only for double-flow mechanical ventilation. This parameter ranges between 0.86 and 0.94 , according to the manufacturers, and may depend on the air flow rate and the operating conditions. In this paper, an average value $\eta_{\mathrm{hr}}=0.9$ is considered, while $\eta_{\mathrm{hr}}=0$ applies to single-flow mechanical ventilation. On the other hand, the annual electricity consumption of the fans can be determined by Eq. (5), starting from the data reported in Table 3 :

$\mathrm{E}_{\mathrm{el}}=\frac{\sum_{\mathrm{k}}\left(\mathrm{P}_{\mathrm{el}, \mathrm{k}} \cdot \mathrm{f}_{\mathrm{k}}\right) \cdot 24 \cdot \mathrm{ND}}{1000}$

Here, ND is the number of days included in heating season. As an example, according to the national regulations about energy savings in residential buildings, in Catania the space heating system can operate only from the $1^{\text {st }}$ of December to the $31^{\text {th }}$ of March, which means ND $=121$ days. Obviously, a mechanical ventilation system may operate all year round; however, in this work attention is paid to the only heating season, when the effects of ventilation on the energy balance are more evident.

In case of natural ventilation, the only relevant contribution comes from Eq. (4). Here, the average rate of ventilation is set to $\bar{n}=1 \mathrm{~h}^{-1}$, which takes into account both the air infiltration and the occasional opening of the windows by the occupants. Of course, the air change rate in natural ventilation depends on several issues, such as the occupants' behaviour and the air tightness of the envelope. However, some literature suggests that $\bar{n}=1 h^{-1}$ is reasonable, especially in mild climates and in not very tight buildings, both circumstances being common in Italy $[17,18]$

After the calculation of the final energy needs (thermal energy plus electric energy), the following step has consisted in the evaluation of the overall annual primary energy consumption. This is determined in terms of $\mathrm{kWh}$ per unit net surface of the dwelling by means of Eq. (6):

$\operatorname{PE}\left(\overline{\mathrm{n}}, \eta_{\mathrm{hr}}\right)=\left[\frac{\mathrm{E}_{\mathrm{th}}\left(\overline{\mathrm{n}}, \eta_{\mathrm{hr}}\right)}{\eta_{\mathrm{th}}}+\frac{\mathrm{E}_{\mathrm{el}}(\overline{\mathrm{n}})}{\eta_{\mathrm{el}}}\right] \cdot \frac{1}{\mathrm{~A}}$

In Eq. (6), the overall efficiency of the space heating system is $\eta_{\text {th }}=0.80$, including the performance of the heat generator and the losses for heat distribution and emission.

On the other hand, the conversion factor from primary energy to electricity distributed to the grid is set to 1.95 $\mathrm{kWh} / \mathrm{kWh}_{\mathrm{el}}$, according to a recent Italian standard [19]. This value refers only to non-renewable primary energy sources, and can be translated into an overall efficiency $\eta_{\mathrm{el}}=1 / 1.95$ $=0.513$ for electricity production and distribution. 
The results of Eq. (4) and Eq. (5) are shown in Fig. 3. Here, one can observe that controlled mechanical ventilation systems introduce a consistent reduction in the overall energy consumption, if compared to natural ventilation. In particular, the thermal energy requirement associated with natural ventilation is $E_{\text {th }}=2138 \mathrm{kWh} /$ year; this value can be drastically reduced with constant-flow $(680 \mathrm{kWh} /$ year $)$ and hygro-adjustable single-flow mechanical ventilation (515 $\mathrm{kWh}$ /year). Moreover, both double-flow configurations make thermal energy needs almost negligible (i.e. below 100 $\mathrm{kWh} /$ year), thanks to the high-efficiency heat recovery unit.

On the other hand, the electricity consumption is not negligible in mechanical ventilation systems, especially in double-flow configuration, due to the operation of two fans and to the pressure losses in the heat recovery unit. The highest value of electricity consumption pertains to the constant double-flow mechanical ventilation system (132 $\mathrm{kWh} /$ year), whereas the single-flow hygro-adjustable system only consumes $35 \mathrm{kWh} /$ year of electricity.

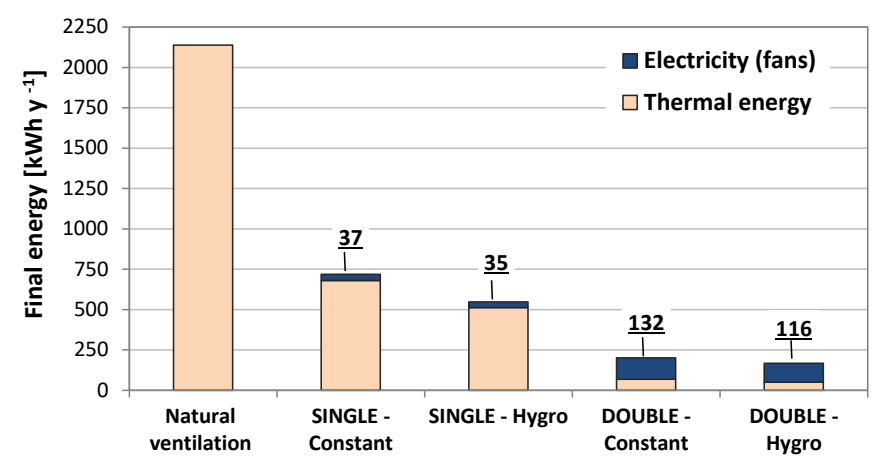

Figure 3. Final energy needs: natural and mechanical ventilation

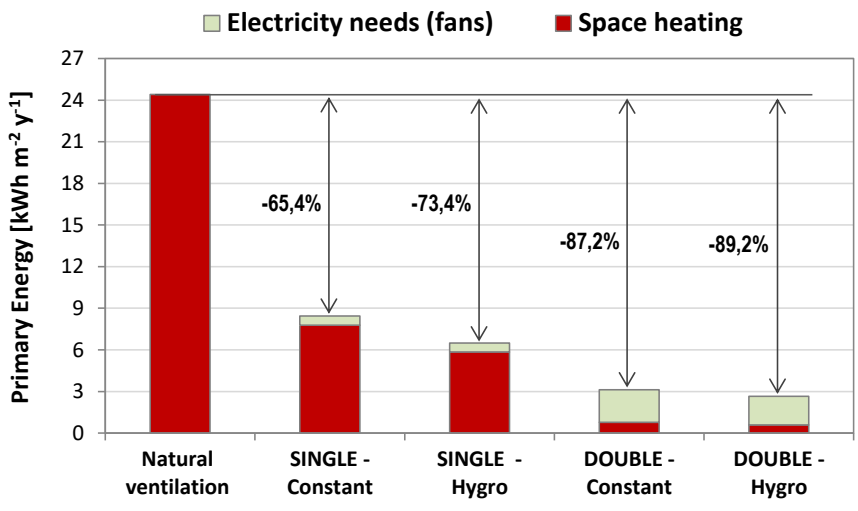

Figure 4. Primary energy consumption: natural and mechanical ventilation

When looking at the primary energy needs, calculated through Eq. (6), all MV configurations enable outstanding savings in comparison with natural ventilation, see Fig. 4. Indeed, primary energy savings range from $65.4 \%$ for the constant single-flow system to $89.2 \%$ for the double-flow hygro-adjustable system.

However, the difference between the two double-flow configurations is not high. Hence, given that the cost of hygro-adjustable terminals is significantly higher than for constant-flow terminals, their adoption may be questionable under a merely financial point of view. This issue is further developed in the next section.

\subsection{Financial issues: the payback time}

The calculation of the annual operating costs of mechanical ventilation systems is the following step to evaluate their financial suitability in residential buildings, if compared to the practice of natural ventilation. Hence, provided that these costs are lower than for natural ventilation, it will be possible to make a balance between the annual savings and the initial investment for their installation.

If looking at the operating costs, these are calculated through Eq. (7). The costs are due to the fuel (natural gas) needed to feed the heat generator - limited to the energy needs for ventilation - and to the electricity consumed by the fans.

$\mathrm{C}_{\mathrm{op}}=\frac{\mathrm{E}_{\mathrm{th}}}{\eta_{\mathrm{th}} \cdot \mathrm{LHV}} \cdot \mathrm{c}_{\mathrm{f}}+\mathrm{E}_{\mathrm{el}} \cdot \mathrm{c}_{\mathrm{el}}$

In Eq. (7), the Lower Heating Value of natural gas is LHV $=9.9 \mathrm{kWh} / \mathrm{m}^{3}$. Moreover, the average unit cost of electricity and natural gas for residential clients is respectively set to $\mathrm{c}_{\mathrm{el}}$ $=0.24 € / \mathrm{kWh}$ and $\mathrm{c}_{\mathrm{f}}=1.15 € / \mathrm{m}^{3}[20]$.

However, the maintenance costs must also be included among the annual costs for the MV systems. Maintenance mostly consists in cleaning the extract and inlet terminals with suitable products, and in cleaning or substituting the filters in the ventilating unit, only for the double-flow systems. Upon consultation with the manufacturers, the maintenance costs are set as $C_{m a}=20 € /$ year for single-flow systems and $\mathrm{C}_{\mathrm{ma}}=40 € /$ year for double-flow systems.

Finally, the simple payback time (SPT) for the proposed mechanical ventilation systems is assessed through Eq. (8):

$$
\mathrm{SPT}=\frac{\mathrm{C}_{\mathrm{in}, \mathrm{mv}}}{\mathrm{C}_{\mathrm{op}, \mathrm{nv}}-\left(\mathrm{C}_{\mathrm{op}, \mathrm{mv}}+\mathrm{C}_{\mathrm{ma}}\right)}
$$

The annual costs resulting from this analysis are shown in Fig. 5. As one can observe, the annual savings provided by mechanical ventilation systems range between $183.1 € /$ year for constant single-flow ventilation to $235.5 €$ /year with hygro-adjustable double-flow ventilation. In fact, double-flow ventilation systems are penalized by the relative high price of electricity in the residential sector. Consequently, the annual costs for double-flow ventilation are not too far from those calculated for hygro-adjustable single-flow, in spite of their much higher initial cost.

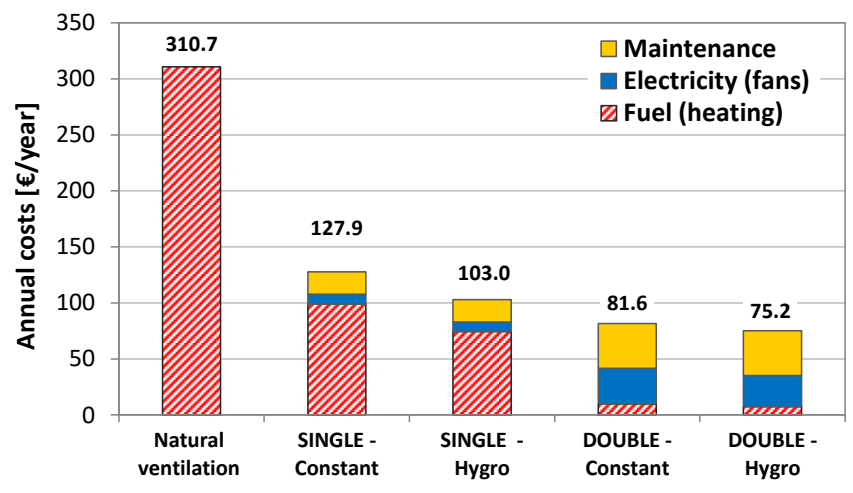

Figure 5. Annual costs: natural and mechanical ventilation 
This result influences the simple payback time, which is around 16 years for double-flow mechanical ventilation systems. On the other hand, the simple payback time is between 6 and 7 years for single-flow mechanical ventilation systems.

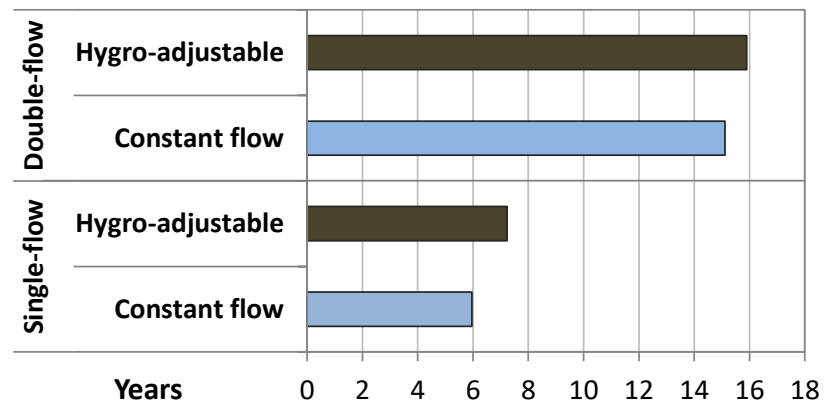

Figure 6. CMV systems: simple payback time

According to these results, single-flow mechanical ventilation systems seems to be much more appealing than double-flow in residential applications, at least in the warm climate considered so far. The role of the climate on the outcomes of the study will be examined in the next section.

\section{INFLUENCE OF THE CLIMATIC CONDITIONS}

The outcomes discussed in the previous section are likely to be different in other climatic contexts. Indeed, as highlighted by Eq. (4), the thermal energy needs for space heating caused by outdoor ventilation is proportional to the Heating Degree Days. Even the electricity demand of the ventilating unit during the heating season is dependent on the climate: in particular, in Italy the duration of the heating season, defined by national regulations, changes according to the number of Heating Degree Days, as reported in Table 4.

Table 4. Definition of the heating season in Italy

\begin{tabular}{lllll}
\hline $\begin{array}{l}\text { HDD } \\
\text { from }\end{array}$ & to & $\begin{array}{l}\text { Dates } \\
\text { from }\end{array}$ & to & $\begin{array}{l}\text { ND } \\
\text { [days] }\end{array}$ \\
\hline 0 & 600 & $01 / 12$ & $15 / 03$ & 105 \\
601 & 900 & $01 / 12$ & $31 / 03$ & 121 \\
901 & 1400 & $15 / 11$ & $31 / 03$ & 137 \\
1401 & 2100 & $01 / 11$ & $15 / 04$ & 166 \\
2101 & 3000 & $15 / 10$ & $15 / 04$ & 183 \\
3001 & - & $01 / 10$ & $30 / 04$ & 212 \\
\hline
\end{tabular}

Thus, in order to understand how the severity of the climate in winter - measured by the HDD - can modify the outcomes discussed in the previous section, the calculations have been repeated by varying the HDD in the range between 750 and 3500 . This range has been chosen because it includes the great majority of the Italian territory, except a few municipalities in the Alpine regions.

The results of this investigation are reported in Fig. 7 (primary energy consumption) and Fig. 8 (simple payback time). To make the results more comprehensible, the position of four representative cities is underlined, namely:

- $\quad$ Catania, Southern Italy (HDD = 833)

- $\quad$ Rome, Central Italy (HDD = 1415)

- $\quad$ Milan, Northern Italy $(\mathrm{HDD}=2404)$
- $\quad$ Bozen, alpine North-Eastern Italy $($ HDD = 2791)

From Fig. 7, one can see that in all climates the use of hygro-adjustable terminals introduces significant primary energy savings if compared to constant-flow, especially in single-flow ventilation systems

On the other hand, from a financial point of view there is little difference between hygro-adjustable and constant flow systems. The reason is that the initial extra-cost for hygroadjustable systems compensates the annual savings for fuel and electricity, thus making the two solutions almost equivalent in terms of SPT (Fig. 8).

However, the main outcome of this analysis is that in cold climates (HDD $>2750)$ the simple payback time for mechanical ventilation converges asymptotically below 2 years for single-flow mechanical ventilation, and below 4 years for double-flow mechanical ventilation (see Fig. 8), thus making them very interesting in financial terms.

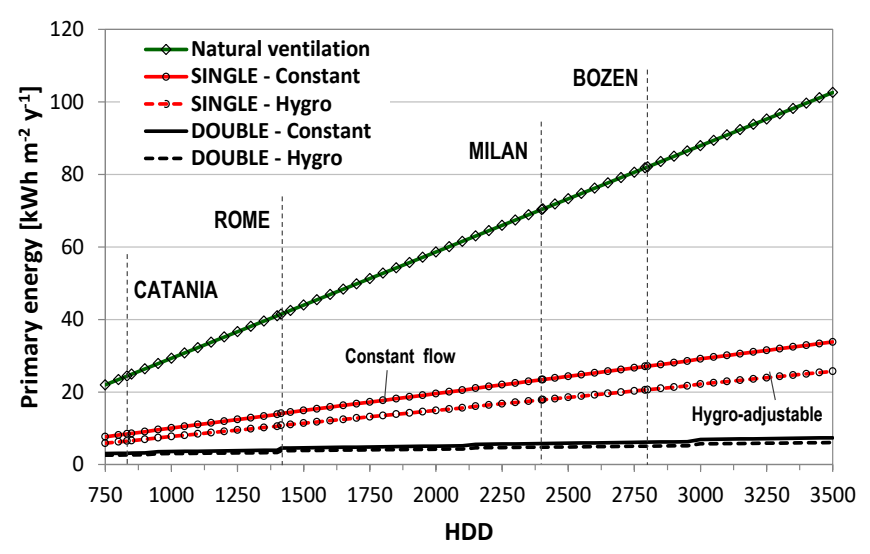

Figure 7. Primary energy consumption vs HDD

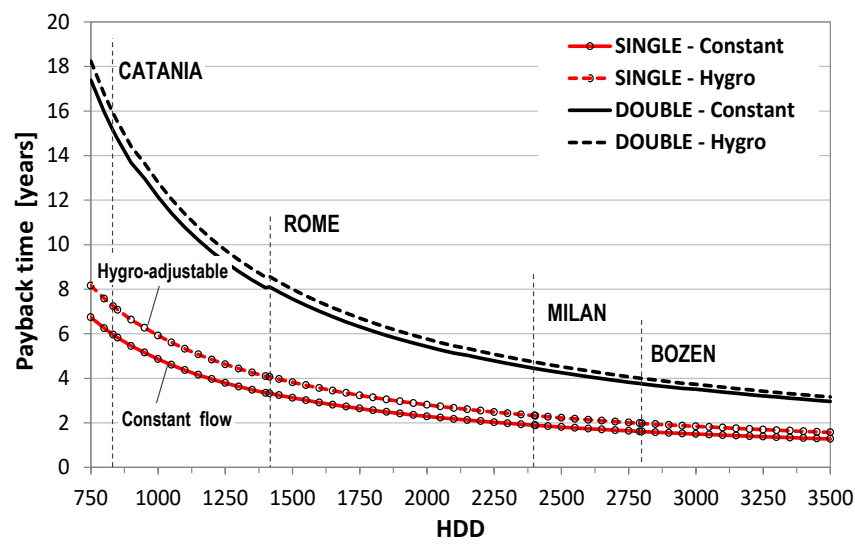

Figure 8. Simple payback time vs HDD

\section{CONCLUSIONS}

As suggested by the outcomes of the paper, controlled mechanical ventilation systems in residential buildings undoubtedly contribute to significantly reduce the primary energy consumption for space heating, while also allowing to provide good indoor air quality.

However, the installation of these systems is not always easy to promote under a financial point of view, especially in warm climates and in case of double-flow ventilation systems. In fact, the simple payback time in localities with HDD < 1000 is above 12 years, which justifies the scepticism 
reported by several surveys in the literature. On the other hand, as the climate gets colder (HDD > 1500), the simple payback time of controlled mechanical ventilation systems becomes more interesting, and finally converges below 2 years for single-flow systems and below 4 years for doubleflow systems.

These results are encouraging, if one considers that warm climatic conditions only occur in the coastal area of the Mediterranean basin, while higher HDD are much more frequent in Italy.

This study has only focused on the energy needs in the heating season. In the cooling season, the thermal energy needs for air-conditioning would be relevant only in warm climates. Here, the ventilation through outdoor air can even play a positive role in terms of passive cooling, if properly exploited when the outdoor temperature is lower than the indoor temperature [21, 22]. In this sense, a mechanical ventilation system can assure an appropriate ventilation rate, without the need to keep windows open through the night, which may generate noise and privacy issues.

In mid-seasons, mechanical ventilation systems might not be used, allowing the building to be free-running during the rest of the year [23].

In any case, the results presented so far are likely to be influenced by several parameters:

- Heating system: the lower its efficiency, the higher the competitiveness of MV systems. The value adopted in this study, which includes distribution and emission losses, is relatively high, as required by recent national regulations. Lower values are not likely to occur, at least in new installations; on the contrary, the value is very likely to improve with condensing heat generators and heat pumps. Hence, these technologies make the adoption of controlled mechanical ventilation systems less interesting;

- $\quad$ Energy efficiency of fans and heat recovery: in this study, high-efficiency heat recovery and ventilating units are considered. The efficiency is not likely to improve significantly in the future, as manufacturers have already made a great effort to reach high levels of performance;

- Air change rate in natural ventilation: this depends on the air tightness of the envelope and on the occupants' behaviour (frequency of window opening). It may also depend on building orientation and shape [24]. The mean value adopted in this study $\left(1 \mathrm{~h}^{-1}\right)$ is reasonable in warm climates and in not very tight buildings, but lower values may occur in cold climates, where buildings are tighter and people tend to avoid frequent window opening. In this case, the comparison becomes less favourable for MV systems;

- $\quad$ Price of electricity: the lower it is, the higher is the competitiveness of MV systems. However, the price of electricity for residential customers has constantly increased in recent years, at an average rate of about $4 \%$ per year; hence, it is very likely to increase further in the future, making mechanical ventilation systems less favourable from a financial point of view;

- $\quad$ Price of natural gas: the higher it is, the higher the competitiveness of MV systems. This price depends on several variables (e.g. annual fuel consumption and geographic area); the value adopted in this study is an average over the Italian territory, and refers to an annual fuel consumption below $200 \mathrm{~m}^{3} /$ year. In other scenarios, the price tends to be lower, making mechanical ventilation systems less favourable from a financial point of view. However, this can be balanced by future cost increases.
It is then evident that the financial attractiveness of controlled mechanical ventilation systems in comparison with natural ventilation has to be evaluated with care case by case.

More detailed studies are being carried out to consider more precisely the air ventilation patterns [25].

\section{REFERENCES}

[1] B. Chenari, J. Dias Carrillo and M. Gameiro da Silva, "Towards sustainable, energy-efficient and healthy ventilation strategies in buildings: a review," Renew Sustain Energ Rev, vol. 59, pp. 1426-1447, 2016. DOI: 10.1016/j.rser.2016.01.074.

[2] K. Engvall, P. Wickman and D. Norbäck, "Sick building syndrome and perceived indoor environment in relation to energy saving by reduced ventilation flow during heating season: a 1 year intervention study in dwellings," Indoor Air, vol. 15, pp. 120-126, 2005. DOI: $10.1111 /$ j.1600-668. 2004.00325.

[3] M. Odriozola-Maritorena, C. García-Gáfaro, C. Escudero, K. Martína and E. Iribara, "Analysis of the influence of the permeability of the envelope in the performance of different types of mechanical ventilation systems," Energy Procedia, vol. 78, pp. 1263-1268, 2015. DOI: $10.1016 /$ j.egypro. 2015.11.273.

[4] E. Kamendere, G. Zogla, A. Kamenders, J. Ikaunieks and C. Rochas, "Analysis of mechanical ventilation system with heat recovery in renovated apartment buildings," Energy Procedia, vol. 72, pp. 27-33, 2015. DOI: 10.1016/j.egypro. 2015.06.005.

[5] E. Kamendere, A. Zandeckis, A. Kamenders, J. Ikaunieks and C. Rochas, "Mechanical ventilation with a heat recovery system in renovated apartment buildings," Agron Res, vol. 12, no. 2, pp. 491-498, 2014.

[6] D. Hekmat, H.E. Feustel and M.P. Modera, "Impacts of ventilation strategies on energy consumption and indoor air quality in single-family residences," Energ Buildings, vol. 9, pp. 239-251, 1986. DOI: 10.1016/0378-7788(86)90024-1.

[7] A. Fukushima and S. Murata, "Push-Pull mechanical ventilation system with heat exchanger controlled by intake air temperature," Energy Procedia, vol. 78, pp. 43-48, 2015. DOI: 10.1016/j.egypro.2015.11.112.

[8] A. Dodoo, L. Gustavsson and R. Sathre, "Primary energy implications of ventilation heat recovery in residential buildings," Energ Buildings, vol. 43, pp. 1566 - $1572, \quad 2011$. DOI: 10.1016/j.enbuild.2011.02.01.

[9] A. Litiu, "Ventilation system types in some EU countries," Rehva Journal, vol. 1, pp. 18-22, 2012.

[10] J.S. Park and H.J. Kim, "A field study of occupant behavior and energy consumption in apartments with mechanical ventilation," Energ Buildings, vol. 50, pp. 19-25, 2012. DOI: 10.1016/j.enbuild.2012.03.015.

[11] M. Baborska-Narozny and F. Stevenson, "Continuous mechanical ventilation in housing - understanding the gap between intended and actual performance and use," Energy Procedia, vol. 83, pp. 167-176, 2015. DOI: 10.1016/j.egypro.2015.12.207.

[12] G. Beko, G. Clausen and C. Weschler, "Is the use of particle air filtration justified? Costs and benefits of filtration with regard to health effects, building 
cleaning and occupant productivity," Build Environ, vol. 43, pp. 1647-1657, 2008. DOI:10.1016/j.buildenv.2007.10.006.

[13] V. Raisa, D. Labaume, E. Longuet and J.F. Nouvel, "Il consumo energetico connesso alla ventilazione degli alloggi: confronto tra sistemi naturali e meccanici”, in Proc. of the $44^{\text {th }}$ International AICARR Conference, Milan, Italy, 2004, pp. 1413-1430.

[14] Impianti aeraulici ai fini del benessere. Generalità, classificazione e requisiti, UNI 10339, 1995.

[15] Ventilation for buildings. Design and dimensioning of residential ventilation systems, CEN TR 14788, 2006.

[16] Journal officiel de la République française, Arrêté du 24 mars 1982 relatif à l'aération des logements (in French).

[17] S. Torabi Moghadam, F. Soncini, V. Fabi and S. Corgnati, "Simulating window behaviour of active and passive users," Energy Procedia, vol. 78, pp. 621-626, 2015. DOI: 10.1016/j.egypro.2015.11.040.

[18] V. Fabi, R. Vinther Andersen, S. Corgnati and B.W. Olesen, 'Occupants' window opening behaviour: a literature review of factors influencing occupant behaviour and models," Build Environ, vol. 58, pp. 188-198, 2012. DOI: 10.1016/j.buildenv.2012.07.009.

[19] Decreto Interministeriale 26 giugno 2015, "Applicazione delle metodologie di calcolo delle prestazioni energetiche e definizione delle prescrizioni e dei requisiti minimi degli edifici" (in Italian).

[20] Autorità per l'energia elettrica, il gas e il Sistema idrico (in Italian).

[21] A. Gagliano, F. Nocera, F. Patania, A. Moschella, M. Detommaso and G. Evola, "Synergic effects of thermal mass and natural ventilation on the thermal behaviour of traditional massive buildings," Int J Sust Energ, vol. 35, no. 5, pp. 411-428, 2016. DOI: 10.1080/14786451. 2014.910517.

[22] A. Gagliano, M. Detommaso, F. Nocera and G. Evola, "A multi-criteria methodology for comparing the energy and environmental behavior of cool, green and traditional roofs," Build Environ, vol. 90, pp. 71-81, 2015. DOI: 10.1016/j.buildenv.2015.02.043.

[23] P. Sassi, "A natural ventilation alternative to the Passivhaus standard for a mild maritime climate," Buildings, vol. 3, pp. 61-78, 2013. DOI: 10.3390/buildings3010061.

[24] C. Delmastro, G. Mutani, L. Schranz and G. Vicentini, "The role of urban form and socio-economic variables for estimating the building energy savings potential at

the urban scale," Int J Heat Technol, vol. 33(4), pp. 91-100, 2015. DOI: 10.18280/ijht.330412.

[25] A. Alkhazaleh and H. Duwairi, "Analysis of mechanical system ventilation performance in an atrium by consolidated model of fire and smoke transport simulation," Int J Heat Technol, vol. 33, no. 3, pp. 121-126, 2015. DOI: 10.18280/ijht.330318.

\section{NOMENCLATURE}

A

c

$\mathrm{C}_{\mathrm{p}}$

$\mathrm{E}$

f

HDD

LHV

$\mathrm{n}$

ND

$P$

PE

q

Q

$\mathrm{RH}$

SPT

$\mathrm{t}$

V

y

\section{Greek symbols}

$\rho$

$\eta$

\section{Subscripts}

el
$\mathrm{f}$
$\mathrm{hr}$
$\mathrm{i}$
in
$\mathrm{ma}$
$\mathrm{mv}$
$\mathrm{nv}$
$\mathrm{o}$
op
th mv net surface area, $\mathrm{m}^{-2}$ unit cost, $€ . \mathrm{kWh}^{-1}, € . \mathrm{m}^{-3}$ specific heat capacity, $\mathrm{J} \mathrm{kg}^{-1} \mathrm{~K}^{-1}$ final energy, $k W h$. year $^{-1}$ fraction of operation, $\%$ heating degree-days, ${ }^{\circ} \mathrm{C}$.days lower heating value of the fuel, $\mathrm{kWh} \cdot \mathrm{m}^{-3}$ air change rate, $\mathrm{h}^{-1}$ number of days, days power, $\mathrm{W}$ primary energy consumption, $\mathrm{kWh}$ year $^{-1}$ rate of $\mathrm{CO}_{2}$ production, L.h ${ }^{-1}$ air flow rate, $\mathrm{m}^{3} \cdot \mathrm{h}^{-1}$ relative humidity, $\%$ simple payback time, years time lapse, $h$ net volume of the building, $\mathrm{m}^{-3}$ $\mathrm{CO}_{2}$ concentration, ppm

density, $\mathrm{kg} \cdot \mathrm{m}^{-3}$

efficiency, -

electricity

fuel

heat recovery

indoor

initial

maintenance

mechanical ventilation

natural ventilation

outdoor

operation

thermal 